\title{
Pupils' Self-Esteem in the Early Years of Education within Different Interventions
}

Marjaana Soininen

Email:marjasoi@utu.fi

\section{Tuula Merisuo-Storm}

Email: tuumer@utu.fi

University of Turku, Finland, Department of Teacher Education, Rauma Unit

\section{Doi:10.5901/jesr.2014.v4n2p83}

\section{Abstract}

Finland, with the population of 5,3 million inhabitants, has a very high standard education system. Kindergarten and class teachers get their education at universities. Kindergarten teachers study up to the bachelor's degree (180 credits) and class teachers up to the master's degree (300 credits). In the past, it was common that these two groups worked separately and hardly had any co-operation. In recent years, it has been noticeable that the gap between these two institutions along with the teachers working in them has narrowed. One explanation can be that administrators have started to see young children's education as a continuum. Recently, in Finland has been made a significant reform concerning education: early childhood education has been moved in most of the communities from the social welfare administration to the administration of education. A remarkable renovation has also been the idea of putting pre-primary and primary education into the same building. In Finland, every child has an opportunity (in theory) to attend a kindergarten but children are obliged to start school during the year when they turn seven. It has been discussed if children should start school earlier because ca. $98 \%$ of the sixyear-olds already participates in pre-primary education. Another main question has been how to make the transfer from kindergarten to school easier for a child.

Keywords: self-esteem, early years of education

\section{Theoretical Framework}

In Finland, National Core Curriculum for Pre-primary Education 2010 (NCCPE) and National Core Curriculum for Basic Education 2004 (NCCBE) are the two important documents, which with the Acts rule the education. At the beginning of their education children differ in many ways; some are quick learners, some need extra hours to learn. For this reason, we have to be aware that not only the learning process is important but also a pupil's motivation towards learning. From the very beginning, we should enhance pupils' self-confidence as learners. It means that we have to build a supporting and positive learning environment, where everyone feels safe and secure. This has to start already at the very beginning of children's learning path. In the core curriculum of pre-primary education is said: "It is important to strengthen children's healthy self-esteem with the aid of positive learning experiences and to provide opportunities for diverse interaction with other people" (NCCPE, p. 5). The mission of basic education presents a similar idea: "Basic education must provide an opportunity for diversified growth, learning, and the development of a healthy sense of self-esteem, so that the pupils can obtain the knowledge and skills they need in life, become capable of further study, and, as involved citizens, develop a democratic society" (NCCBE, p. 12).

"A child's healthy self-esteem will be strengthened with the aid of positive learning experiences and encouraging feedback, while also providing opportunities for diverse interaction. Attention shall be paid to the early identification of learning barriers and difficulties. It is necessary to recognise factors relating both to individual children and to the implementation and operating environment of pre-primary education." (NCCPE, p.16.)

Since the idea is that early childhood education and care, pre-primary education, and basic education form an integrated continuum enhancing a child's overall development, municipalities should provide different flexible forms of education. On page 18 in NCCPE it has been said: "Any support needs in terms of growth and learning are met by differentiating instruction, through co-operation between teachers and by modifying pre-primary groups in a flexible 
manner." These two documents (NCCPE and NCCBE) were in main role when constructing the interventions described in this article.

Healthy self-esteem and good motivation are two important facts connected to learning. First, we have to define the term self-esteem. The task is not easy, since there does not exist common agreement of its meaning. One of the most well-known researchers in this area is Rosenberg (1979) who has claimed that "self-esteem is based on selfassessments of qualities that are perceived as important or psychologically central by individuals". His conceptual definition of self-esteem was thus seen as one-dimensional approach, and it was understood as global self-esteem. Tafarodi and Milne (2002) argue that there are at least two dimensions - self-competence and self-liking, and that there is a lack of formal recognition of this duality. This is based on their literature survey covering different definitions, theories and models of self-esteem. Reasoner (1992) had already ten years before Taforodi's and Milne's work found over a hundred definitions of self-esteem. There are many reasons why it is so difficult to reach agreement in conceptualizing self-esteem. The following quotation from Reasoner (2010) reveals well the complexity of the term: "some have seen it as a psychodynamic, developmental process; others have approached it from the perspective of the cognitive-behaviorist in terms of various coping strategies; others have viewed it from the position of a social psychologists in terms of attitudes; while others have focused on the experiential dimensions of self-esteem as a humanistic psychologist."

According to Reasoner (2010) there is a general agreement that self-esteem includes cognitive, affective, and behavioral elements. This has a connection to Bloom's (1976) idea about the holistic view of a learner. Hewitt (2007) defines self-esteem as the affective or emotional dimension of self-objectification. He states that the concept summarizes both positive and negative attitudes pupils may have towards themselves, and it appears to have a connection with mood. This raises a question: how stable self-esteem is when we are assessing pupils' self-esteem during their early years of education? Self-esteem starts to develop already at home before children enter formal education. To enhance children's self-esteem, adults who are supervising them need a strong and healthy self-esteem themselves.

The theoretical background of our study is based on the five-stage model of self-esteem by Michele Borba (1989; 1994) and Robert Reasoner (2010). According to them strong, healthy self-esteem is built on five building blocks: security, selfhood, affiliation, mission and competence. Sense of security means that a person (in this case a child) has a feeling of strong assuredness; he or she feels comfortable and safe. A child also knows what is expected of him or her, and he or she is able to depend on other individuals in different situations, and he or she comprehends rules and limits. Sense of selfhood is a feeling of individuality, which means that a person is acquiring self-knowledge that includes an accurate and realistic self-description in terms of roles, attributes and physical characteristics. Sense of affiliation is a feeling of belonging, acceptance or relatedness. It is also a feeling of being approved of, appreciated and respected by others. Sense of mission is a feeling of purpose and motivation. It can be seen also as self-empowerment through setting realistic and achievable goals. It means that a person is willing to take responsibility for the consequences of one's decisions. Sense of competence is a feeling of success and accomplishment in things that are regarded as important or valuable. A person is aware of one's strengths and he or she is also able to accept one's weaknesses. The model can also be called an empowerment cycle. Parents and teachers play an important role in enhancing children's self-esteem.

Figure 1: The five-stage model of self-esteem

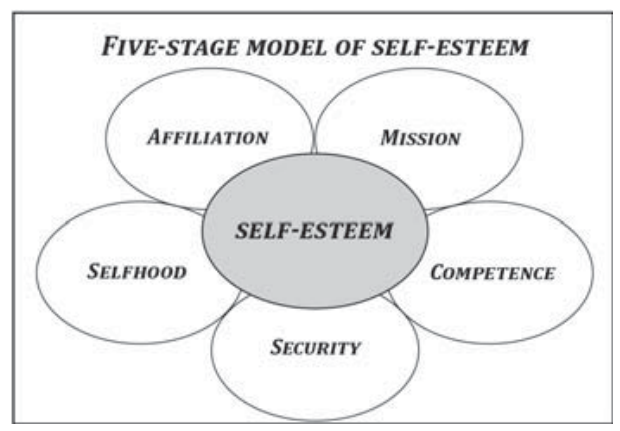

\section{Interventions}

During the academic years 2010 - 2011 and 2011 - 2012 the Finnish National Board of Education funded the JEKKU 
project (Flexible start in early years of education) in which six municipalities in south-western Finland built a network to ease children's transfer from kindergarten to school environment. The interventions were: (1) Flexible groupings and teachers' co-operation, (2) Home-school partnership, (3) The fluent continuum from pre-school to school, (4) Active cooperation between different parties at transition stage, (5) Flexible school start, (6) Three years for first and second grade, (7) Reading marketplace, (8) Word hunt, and (9) Fairy tale in the back bag. These interventions were constructed based on the ideas of NCCPE and NCCBE.

The aims of the first intervention were: to carry out the three-stage support, teachers' well-being, and shared teaching. The first grade teachers, teaching aids and a special education teacher shared the responsibility. Since all the first grade classes were located along one hallway, the teaching personnel could group pupils according to their qualities and learning skills, or all pupils could be taught in one group. This model allowed using the teachers' strengths efficiently. The aims of the second intervention were: to create new models that enhance the support of the adults working with children, to enhance the co-operation with guardians and the personnel of day care, school, child health clinic, school health care, and the community, as well as to promote the detection of the need for early support. The location of the school at the center of the village gave the idea to gather members from above mentioned groups to deepen their partnership. Also the kindergarteners, the first and the second graders worked at the same school building. The aims of the third and the fourth interventions were to create a more flexible and open co-operation between pre-school and primary groups, make the transfer from pre-school to school easier, and to enhance working motivation and joy of the personnel. Since these schools were located in the same municipality teachers and other school personnel could cross the borders and work side by side creating reading circles, drama workshops, active mathematic lessons etc. The main idea of the fifth intervention was that all the children can start their education during the year they turn seven and no one's school start is postponed. The aim is to support a child who has difficulties in learning by using multi-professional help and peer learning. The focus of teaching is that every child is seen and heard. Also music, dance and movement therapy is used as a method to attain a peaceful learning environment. The main aims of the sixth intervention were to give a pupil three years to cover the content of the first and the second grade. Special attention is paid in enhancing social skills, working skills, and learning strategies. The aims of the seventh intervention are much the same as previously mentioned but learning to read and to write was especially emphasized. Language skills are learned in groups that support a child's individual needs. The aims of the eight and the ninth interventions were: to prevent reading and writing disabilities, reading stories every day to increase children's vocabulary and story composing skills.

\section{AlM of the Study}

Several studies related to the project were conducted by the department of teacher education in Rauma, one of them is reported in this article. The main research aim was to find out how healthy pupils' self-esteem is at the beginning of their education. The specific questions are: (1) Are there differences in the boys' and the girls' self-esteem? (2) Are there differences between different intervention groups?

\section{Instrument and Data}

A 50-item quantitative self-report questionnaire was constructed based on the five-stage model of Michele Borba (1989) and the ideas of self-esteem of Robert Reasoner (2010) measuring security, selfhood, affiliation, mission, and competence. The questionnaire was child friendly with agree and not agree options. The overall score range was $0-50$, and a subscale score range $0-10$. The reliability of the instrument was good 0.82 (Cronbach's alpha coefficient). Altogether 503 children ( 251 boys and 252 girls) were tested. The testing took place at the spring semester 2011 . At the time of testing $8 \%$ of children attended pre-school, $63 \%$ first grade and $29 \%$ second grade. The children were from 6 to 9 years old. The main interest in this article was to find out if there are differences in the self-esteem of the pupils attending different interventions. The nine interventions mentioned above were divided into three groups: Flexible $(n=354)$, Reading ( $n=99)$, and Three-year $(n=50)$ group. The first five interventions described above formed the Flexible group, the interventions $7-9$ the Reading group, and the sixth intervention (there were several schools) was named the Three-year group. 
Table 1: Examples of statements in five subscales of self-esteem questionnaire

\begin{tabular}{|c|c|c|}
\hline \multicolumn{3}{|l|}{ SECURITY } \\
\hline 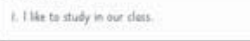 & $6 x$ & $\ddot{\imath} \ddot{b}$ \\
\hline 5. libow to atom l cen trate. & Sस & $\because \ddot{\sigma}$ \\
\hline \multicolumn{3}{|l|}{ SELFHOOD } \\
\hline 14. I lie enyed. & (29) & $\ddot{\theta} \ddot{\theta}$ \\
\hline 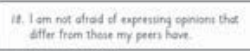 & 200 & $\ddot{ن} \ddot{\sigma}$ \\
\hline \multicolumn{3}{|l|}{ AFFILATION } \\
\hline 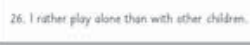 & & $\ddot{\theta} \ddot{\sigma}$ \\
\hline 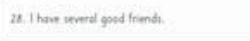 & & $\ddot{\ddot{\theta}}$ \\
\hline \multicolumn{3}{|l|}{ MISSION } \\
\hline 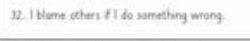 & & $\ddot{i} \ddot{6}$ \\
\hline 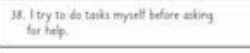 & & $\ddot{\bullet} \ddot{\sigma}$ \\
\hline \multicolumn{3}{|l|}{ COMPETENCE } \\
\hline 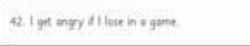 & C & $\ddot{\theta}$ \\
\hline 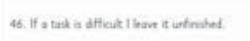 & & $\ddot{ن} \ddot{\dot{\theta}}$ \\
\hline
\end{tabular}

\section{Results}

Firstly, the focus was on pupils' ( $n=503)$ self-esteem and if there are differences in the boys' $(n=251)$ and the girls' $(n=252)$ self-esteem.

Table 2: Means, standard deviations, and t-test values between boys and girls in self-esteem

\begin{tabular}{|c|c|c|c|c|c|c|c|c|}
\hline $\begin{array}{c}\text { SENSE OF } \\
\text { SELF-ESTEEM }\end{array}$ & $\begin{array}{c}\text { ALL } \\
\mathrm{x}\end{array}$ & $\mathrm{s}$ & $\begin{array}{c}\mathrm{BOYS} \\
\mathrm{x}\end{array}$ & $\mathrm{s}$ & $\begin{array}{c}\text { GIRLS } \\
\mathrm{x}\end{array}$ & $\mathrm{s}$ & I-value & $\mathrm{p}$ \\
\hline Security & 7.90 & 1.53 & 7.63 & 1.62 & 8.10 & 1.38 & -3.49 & .001 \\
\hline Selfhood & 7.93 & 1.88 & 7.55 & 1.88 & 8.32 & 1.77 & -4.74 & .000 \\
\hline Affiliation & 8.55 & 1.79 & 8.23 & 2.01 & 8.90 & 1.51 & -4.12 & .000 \\
\hline Mission & 7.50 & 1.79 & 7.25 & 1.79 & 7.71 & 1.77 & -2.86 & .004 \\
\hline Competence & 7.41 & 1.65 & 7.28 & 1.70 & 7.54 & 1.56 & -4.16 & .000 \\
\hline
\end{tabular}

As Table 2 shows, children seem to have very positive and healthy self-esteem at the beginning of their education. In all five areas of self-esteem, the girls score more positive than the boys, the difference being statistically significant $(p=.004$ $-.000)$. Within the both genders, the highest scored subarea is affiliation and the lowest competence.

In the next table 3 is shown the results between Reading $(n=354)$ and Flexible $(n=99)$ groups, and between the different genders. In the Three-year group, the number of the pupils was so small that it was left out of this comparison, and only the mean value of the whole group is presented.

Table 3: Boys' and girls' sense of self-esteem in reading and flexible groups

\begin{tabular}{|c|c|c|c|c|c|c|c|}
\hline \multirow{2}{*}{$\begin{array}{l}\text { SEVSE OF } \\
\text { SELF-ESTEEM }\end{array}$} & \multirow[b]{2}{*}{ gender } & \multicolumn{2}{|c|}{ READING } & \multicolumn{2}{|c|}{ FLEXIBLE } & \multirow[b]{2}{*}{ t-value } & \multirow[b]{2}{*}{$p$} \\
\hline & & $x$ & 8 & $x$ & $s$ & & \\
\hline \multirow[t]{2}{*}{ Security } & boys & 7.91 & 1.62 & 7.59 & 1.63 & & \\
\hline & girts & 8.26 & 1.42 & 8.11 & 138 & .3 .18 & .002 \\
\hline \multirow[t]{2}{*}{ Selfhood } & boys & 780 & 2.08 & 7.50 & 1.80 & & \\
\hline & girls & 8.38 & 1.98 & 8.33 & 1.75 & 4.34 & .000 \\
\hline \multirow[t]{2}{*}{ Affitiation } & boys & 7.86 & 2.23 & 8.34 & 1.84 & & \\
\hline & girls & 8.64 & 1.72 & 8.96 & 1.47 & $-3,45$ & .001 \\
\hline \multirow[t]{2}{*}{ Mission } & boys & 2.64 & 1.71 & 7.18 & 1.72 & & \\
\hline & gints & 7.68 & 1.92 & 7.77 & 1.75 & .3 .13 & .002 \\
\hline \multirow[t]{2}{*}{ Competence } & boys & 6,73 & 1.97 & 7.39 & 1.65 & & \\
\hline & gints & 7.29 & 1.80 & 2.63 & 1.53 & -1.42 & .155 \\
\hline
\end{tabular}


The reading group $(X=39,65, \mathrm{~s}=6.74)$ and the flexible group $(X=39.51, \mathrm{~s}=6.05)$ do not have a statistically significant difference in the self-esteem. In the Reading group (Table 3 ) there are no statistically significant differences between the boys and the girls in different senses of self-esteem. However, in the Flexible group statistically significant differences can be seen between the two genders in selfhood, affiliation, security, and mission. The mean of the Three-year group was much lower $(X=36.53, s=6.49)$. The self-esteem of this group differed from the other groups at the level 0.05 $(F=3.268, p=.039)$. The box plots in Figure 2 show the differences of the groups in the whole self-esteem and in each five senses.

Figure 2: Box plots between three intervention groups in self-esteem
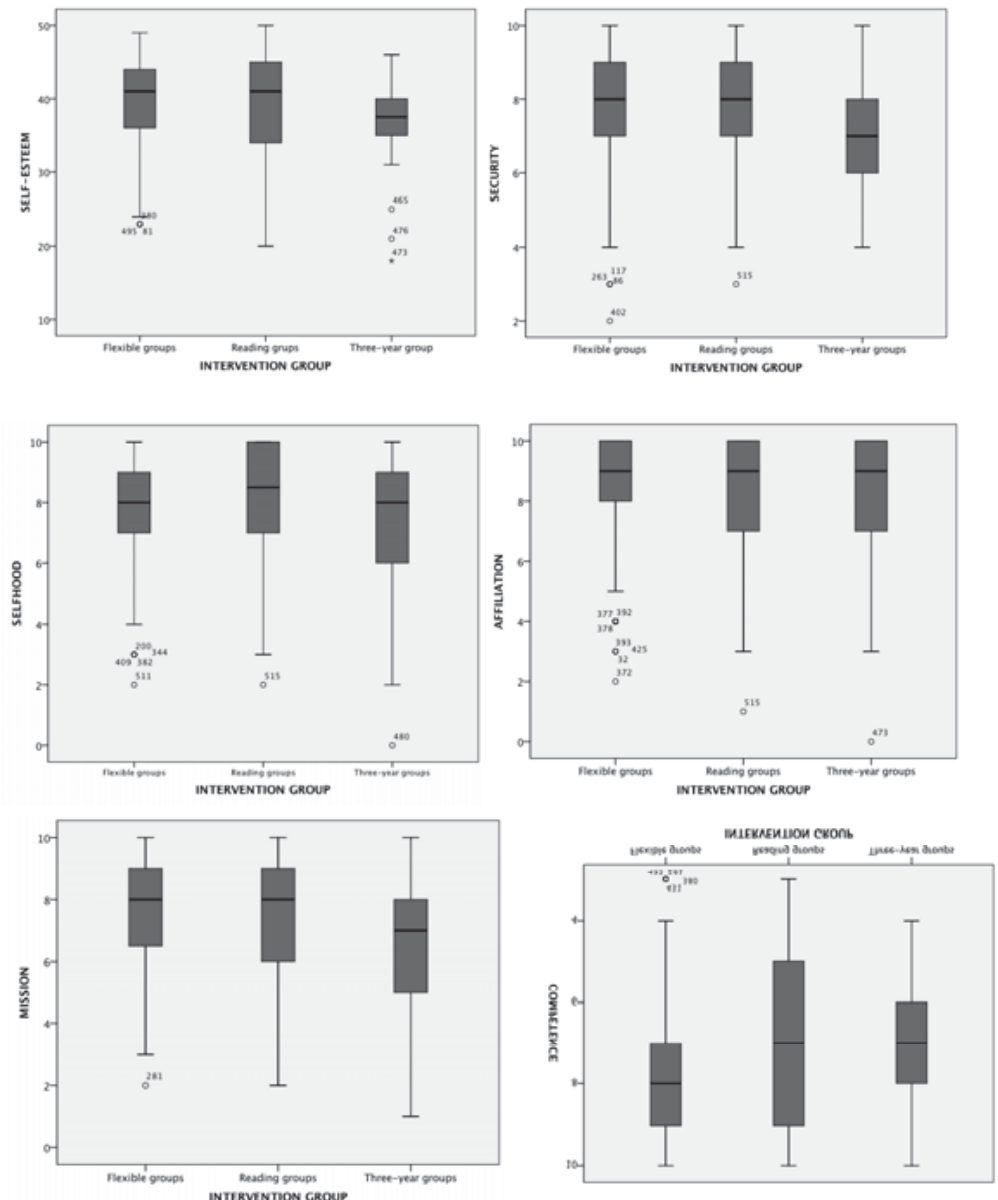

It is important that the learning environment is safe. The results show that the girls felt safer at school than the boys (Table 3). In addition, the pupils in different intervention groups seem to differ in the sense of security. The maximum score 8.43/10 was attained in the topic group "Fairy tale in the back bag" in which the main objectives were to enhance the pupils' literacy skills and co-operative learning. In this school, the overall self-esteem was the best (41.09/50). Also the two other schools concentrating on reading scored high in the sense of security. One class in the three-year group had the weakest sense of security (6.82/10) as well as the overall self-esteem (34.10/50). The Fairy tale group scored highest in selfhood (8.56/10), the lowest score being in one of the three-year classes (6.33/10). In average, all pupils scored highest in the sense of affiliation, the mean variation being $7.46-9.27$. This is an interesting result, since both the lowest and the highest scores were attained by pupils in the classes of the Three-year group. In the fourth sense of sellesteem, mission, the highest score was attained in the Word hunt group (8.42/10) and the lowest score $(6.00 / 10)$ in one 
of the Three-year classes. Among the five stages of self-esteem, the competence scored lowest, the variation being from $6.25 / 10$ (in the Three-year group) to 7.87/10 (in the Flexible start group).

The following figures illustrate Pearson's correlation coefficients between different senses of self-esteem.

Figure 3: Pearson's correlation coefficients between different senses of self-esteem

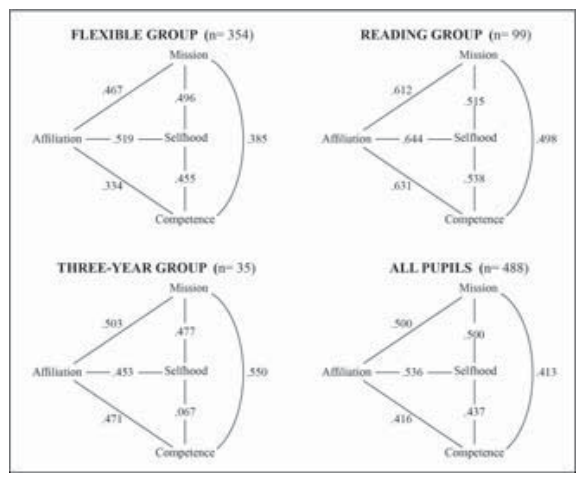

The correlations show that in the Reading group the sense of affiliation correlates strongly with the sense of selfhood, the sense of competence, and the sense of mission. Also the correlation between the sense of mission and the sense of competence is stronger in the Reading group than in the Flexible group. All the correlations are significant at the 0.01 level (2-tailed) except the correlation between selfhood and competence in the Three-year group. In this group security did not correlate significantly with other four senses of self-esteem. In the Flexible group, the Reading group and among all the pupils the sense of security did not correlate with other senses as strongly as shown in the figures above.

\section{Conclusion}

Children have a very healthy self-esteem at the beginning of their education. Looking at the results closer, it is interesting to notice that the strongest building block of self-esteem is the sense of affiliation (Borba 2000), which is also called the sense of belonging (by Reasoner 2010). This means that the children have started to understand what friendship means. They also enjoy working in a team and are comfortable in group settings. Some of the groups were small and the testing took place at the end of the semester. Consequently, the children had already had time to learn to know their peers and teachers. This could be the explanation for the positive result. The sense of affiliation correlates strongly with the sense of selfhood, which is also called as identity (see Reasoner 2010). It is obvious that if a child has a positive self-concept and a strong sense of self it reflects how he or she behaves in a group. These years (age $6-9$ ) are important in forming one's individuality. At this stage, a child is sensitive and reflects his or her behavior with others similar age. Also the feedback given by adults is important. Children have to learn also to accept criticism and to acknowledge their own weaknesses and strengths.

According to Borba $(1989 ; 1994)$ the sense of security is the most important in building one's self-esteem. Security means trust as well as physical and emotional safety at home and at school. The results of this study show that the sense of security is positive but there is something that makes children to give also negative answers. Since the children were at the beginning of their academic education, there is so much new they have to learn; new rules, how to behave in a new learning environment, how meet new adults etc. The correlations show that the sense of security had the weakest connection to any other senses of self-esteem.

The sense of mission, which is also called the sense of purpose plays an important role in a child's learning. Already at a very young age it is possible to teach children how to set appropriate goals for themselves. In setting these goals, parents and teachers play a significant role; they have to encourage children to think about their learning. There is a strong connection between the sense of mission and the sense of competence, which Reasoner (1992) sees similar as self-efficacy, the concept used by Bandura (1986). Although the sense of competence seemed to be positive, it was the lowest of all five senses of self-esteem. This result is understandable since the children are just learning to learn. Making choices and decisions, identifying options, and applying problem solving skills at this early age can be very hard.

The results of the study showed that different learning settings can enhance the self-esteem of children as seen in 
reading interventions. The Flexible group was too wide to tell the effectiveness of a certain intervention and the Threeyear group was too small to draw any conclusions. Consequently, more analyzes are needed.

\section{References}

Bandura, A. (1986). Social foundations of thought and action. Englewood Cliffs, NJ: Prentice-Hall.

Bloom, B. S. (1976). Human characteristics and school learning. New York: McGraw-Hill.

Borba, M. (1989). Esteem Builders. A K - 8 Self- Esteem Curriculum for Improving Student Achievement, Behavior and School Climate. Torrance, CA: Jalmar Press.

Borba, M. (1994). Home Esteem Builders. Torrance. CA: Jalmar Press.

Borba. M. (2000). Strengthening at Risk Students Self-Esteem: What Works! A workshop material. Helsinki, Finland 2.8.2000

Hewitt, J. P. (2007). Self and Society. A Symbolic Interactionist Social Psychology. Boston: Allyn and Bacon. National Core Curriculum for Basic Education 2004. Helsinki: Finnish National Board of Education. National Core Curriculum for Pre-primary Education 2010. Helsinki: Finnish National Board of Education.

Reasoner, R. W. (1992). Building Self-Esteem in the Elementary Schools. Teacher's Manual. Palo Alto, CA: Consulting Psychologists Press.

Reasoner, R. W. (2010). The true meaning of self-esteem. (National Association for Self-esteem) Available online at Http://www.selfesteem-nase.org/whatisselfesteem.shtml.

Rosenberg, M. (1979). Conceiving the self. New York: Basic Books.

Tafarodi, R. W. \& Milne, A. B. (2002). Decomposing Global Self-Esteem. Journal of Personality 70(4), 443 - 483. 